\begin{tabular}{c|c|c}
\hline \hline & MARINE ECOLOGY PROGRESS SERIES \\
Vol. 269: 49-59, 2004 & Mar Ecol Prog Ser & Published March 25 \\
\hline \hline
\end{tabular}

\title{
Allee effects in marine systems
}

\author{
Joanna Gascoigne ${ }^{1,2, *}$, Romuald N. Lipcius ${ }^{2}$ \\ ${ }^{1}$ Virginia Institute of Marine Science, College of William and Mary, Askew Street, Gloucester Point, Virginia 23062, USA \\ ${ }^{2}$ Present address: School of Ocean Sciences, University of Wales Bangor, Menai Bridge, PO Box 1346, Anglesey LL59 5AB, UK
}

\begin{abstract}
The fitness or population growth rate of populations with Allee effects increases with increasing population size or density up to a certain threshold. Allee effects are possible in marine populations, as they are less open than has been assumed and may have a metapopulation structure. We modelled the population consequences of Allee effects and show that increases in mortality interact with critical Allee thresholds, such that an Allee effect with no population consequences at low mortality can drive a population to extinction when mortality is increased. In heavily fished species, populations with strong Allee effects go extinct at lower levels of fishing mortality, or conversely as fishing mortality increases, weaker Allee effects can drive population to extinction. We found little empirical evidence in the literature for widespread Allee effects in marine populations, although we found some suggestive observations, particularly for broadcast spawners and in exploited populations This might be due to methodological problems or long time lags. Many marine species have components of their life history or ecology which could in theory generate Allee effects; however the population level consequences of these potential mechanisms remains virtually unexplored. We suggest that including Allee effects in models of vulnerable populations may be critical for the precautionary management of exploited and threatened marine species.
\end{abstract}

KEY WORDS: Allee effects · Positive density dependence $\cdot$ Inverse density dependence $\cdot$ Depensation

Resale or republication not permitted without written consent of the publisher

\section{INTRODUCTION}

\section{What are Allee effects?}

An Allee effect occurs when some component of individual fitness deteriorates as population density or size decreases towards zero (Allee 1938, Stephens et al. 1999), resulting in a positive density dependent relationship. Standard population models assume that fitness increases as density declines (negative density dependence), but there are various processes that can reduce fitness when there is a dearth of conspecifics (e.g. a lack of mating encounters, failure of fertilisation for broadcast spawners or wind pollinated plants, inbreeding depression; see Fowler \& Baker 1991, Stephens et al. 1999 for reviews).

If there is an Allee effect in some component of fitness, there may also be a decline in per capita population growth rate at small population size or low density. If the population growth rate becomes negative, there will be a critical population size or density below which the population cannot sustain itself (Courchamp et al. 1999). An
Allee effect in some component of fitness (e.g. output of fertilised eggs) may or may not result in a decline in the population growth rate, since it may be balanced by negative density dependence in other components of fitness (e.g. survival or growth). Stephens et al. (1999) distinguish between 'component' Allee effects (positive density dependence in some component of individual fitness) and 'demographic' Allee effects (positive density dependence in the per capita population growth rate). Component Allee effects may or may not lead to demographic Allee effects. Note that 'depensation' has been used in the fisheries' literature to refer to positive density dependence, either through predation or reproduction (e.g. Peterman \& Gatto 1978, Myers et al. 1995, see general discussion in Hilborn \& Walters 1992), by analogy with compensation (negative density dependence). Depensatory mortality in populations is equivalent to a demographic Allee effect.

Component Allee effects can arise from various processes, such as reproductive strategies (Levitan et al. 1992, Shepherd \& Brown 1993, Kuussaari et al. 1998, Petersen \& Levitan 2001), predator-prey interactions 
(Kenward 1978, Calvert et al. 1979, Foster \& Treherne 1981, Inman \& Krebs 1987) or social systems (Halliday 1980, Clutton-Brock et al. 1999, Courchamp et al. 2000a,b, Courchamp \& Macdonald 2001). Conservation biologists and managers are usually more interested in demographic Allee effects, because they ultimately govern extinction or recovery probability of species at low abundance.

\section{Are Allee effects likely in marine systems?}

Marine populations have generally been considered to be open with large effective population sizes, because most marine taxa have planktonic larvae that spend days to months in the water column and are therefore capable of wide dispersal. Allee effects have thus been assumed to be relatively unimportant. However, for many species, larvae may be retained locally, which produces relatively closed populations (Jones et al. 1999, Swearer et al. 1999, Barber et al. 2000, Cowan et al. 2000), and many species have fragmented or dramatically reduced populations (Myers \& Worm 2003), rendering them susceptible to Allee effects.

Allee effects may occur at small population size or low population density. Most marine populations are probably metapopulations with subpopulations connected by larval transport (Lipcius et al. 1997, 2001, Crowder et al. 2000). Allee effects related to density (such as encountering conspecifics for reproduction) can still exert an effect on large populations or on metapopulations if population density has declined to low levels. Allee effects related to population size are also possible in large populations and metapopulations if they depend on the size of the local subpopulation rather than on the metapopulation as a whole (e.g. predator dilution effects). Local population size and density may interact, as for fertilisation success in broadcast spawning sea urchins, where an effect of density is exacerbated by small population size (Levitan $\&$ Young 1995). Allee effects on subpopulation growth rate can also cause metapopulation level 'Allee effects' on a larger spatial scale, with a critical number of subpopulations below which the metapopulation will go extinct (Courchamp et al. 2000a). Hence, the postulated large size and metapopulation structure of marine populations is not necessarily a protection against Allee effects, and Allee effects may in fact operate in a more or less similar way in marine and terrestrial systems.

\section{Allee effects and human impacts on marine systems}

Populations that are naturally susceptible to Allee effects are under selective pressure to evolve mecha- nisms to avoid them (e.g. large eggs, long-lived sperm, and aggregation or spawning synchrony in the case of broadcast spawners; Yund 2000). The simplest way of avoiding Allee effects is to maintain a large or dense, and stable population - if the population is never small or at low density, Allee effects never become relevant. Allee effects could still be 'latent' in the population, should population size or density be reduced - there may exist a component Allee effect (a mechanism for an Allee effect), but the population is not small or sparse enough for the mechanism to create a demographic Allee effect.

Top-down predation by humans has become a dominant force in almost every marine ecosystem (Dayton et al. 1998, Pauly et al. 1998, Jackson et al. 2001), even in remote locations and at what is normally considered low levels of fishing intensity (biomass at $95 \%$ of unfished levels; Jennings \& Polunin 1996). Numerous species have been fished to greatly reduced population levels; in 1994, the FAO considered $25 \%$ of the world's exploited marine resources to be 'overexploited', 'depleted' or 'recovering', with another $44 \%$ 'heavily or fully exploited' (Garcia \& Newton 1997), and the situation has deteriorated since then (Watson \& Pauly 2001, Myers \& Worm 2003). Hence, population dynamics at small population size or low density have recently become important for marine species in a way that is unprecedented in 'natural' systems through their evolutionary history.

Some marine species have also been severely reduced through disease outbreaks. The causes are frequently anthropogenic, either directly by introduction of diseases into new areas (e.g. the oyster disease agents Bonamia ostreae and Haplosporidium nelsoni; Ford \& Tripp 1996), or indirectly through land use and desertification (e.g. mass mortalities of Acropora corals and the Caribbean long-spined sea urchin Diadema antillarum; Shinn et al. 2000), although this idea is controversial.

It is important to know how anthropogenic factors that increase mortality interact with latent or component Allee effects. Exploited or perturbed populations are the logical place to look for empirical evidence of demographic Allee effects in marine systems. We developped a model to quantify the interaction between Allee effects, exploitation and critical thresholds. We then examined the published evidence for Allee effects in marine populations.

\section{MODEL DESCRIPTION}

We used a matrix population model (Caswell 2001) with density dependent reproduction to examine the interaction between Allee effects, critical thresholds and exploitation. The core of the model is a transition 
matrix that defines transition probabilities within and between each stage of the life history, as determined by rates of survival, maturation and reproduction. A vector representing the population size at time $t$ is multiplied by the transition matrix (Table 1 ) to obtain the projected population at time $t+1$, and so on for the desired number of iterations.

This model has 2 stages: juvenile and adult. Individuals move from juvenile to adult at a rate determined by the time to maturity $(\tau)$. Adults reproduce at a per capita rate $\alpha$-in this case, $\alpha$ incorporates the production of embryos and survival up to the juvenile stage. Individuals in each stage have a natural mortality rate $\mathrm{M}_{\mathrm{j}}$ (juveniles) and $\mathrm{M}_{\mathrm{a}}$ (adults), resulting in survival probabilities $e^{-\mathrm{Mj}}$ and $e^{-\mathrm{Ma}}$. This definition of mortality is usual in fisheries science, and has the advantage that different sources of mortality are additive. In addition to natural mortality, adults suffer a fishing mortality rate $F$, resulting in an overall adult survival probability of $e^{-(\mathrm{Ma}+\mathrm{F})}$. For simplicity, density dependence was only added to reproduction, though the effect of density dependence in the juvenile stage is qualitatively similar.

We added density dependence to the model in reproduction only, for simplicity. Elsewhere, we have found that density dependent reproduction and juvenile mortality have similar qualitative population consequences. Mortality from exploitation may be negatively density dependent (if fishers aggregate in high density areas) or positively density dependent or density independent (if fishers are not completely free to choose a fishing area). Here, we assume it is density independent. The model is appropriate for iteroparous species without a fixed life span; other life histories can be accommodated by changing the parameters (Table 1).

We added density dependence in reproduction as follows:

$$
\begin{gathered}
\text { Per capita reproductive output }= \\
\alpha N_{t}^{(\delta-1)} /\left(1+\beta N_{t}^{\delta}\right)
\end{gathered}
$$

where $N_{t}=$ adult density at time $t, \delta=$ Allee effect parameter, maximum reproductive output and $\beta$ sets the slopes and intersection point of the curves (Table 2).

When $\delta=1$, Eq. (1) collapses to $\alpha /\left(1+\beta N_{t}\right)$, which results in negative density dependence. Increasing $\delta$ any amount above 1 adds positive density dependence at low density (a component Allee effect in reproduction). Larger values of $\delta$ intensify the Allee effect by

Table 1. Transition matrix for the density independent version of the model $M_{\mathrm{j}}=$ mortality of juvenile stage, $M_{\mathrm{a}}=$ mortality of adult stage, $\tau=$ time to maturity, $\alpha=$ reproductive output of adults

\begin{tabular}{|cc}
$\mathrm{e}^{-M_{\mathrm{j}}}(1-1 / \tau)$ & $\alpha$ \\
$\mathrm{e}^{-M_{\mathrm{j}}}(1 / \tau)$ & $\mathrm{e}^{-M_{\mathrm{a}}}$
\end{tabular}

Table 2. Transition matrix for density dependent Allee effect model $; \delta=$ Allee effect parameter, $\alpha=$ maximum reproductive output, $\beta=$ scaling factor, $M_{\mathrm{j}}=$ mortality of juvenile stage, $M_{\mathrm{a}}=$ mortality of adult stage, $\tau=$ time to maturity
$\mathrm{e}^{-M_{\mathrm{j}}}(1-1 / \tau)$
$\mathrm{e}^{-M_{\mathrm{j}}}(1 / \tau)$

$$
\begin{gathered}
\alpha N_{\mathrm{a}}^{\delta-1} /\left(1+\beta N_{\mathrm{a}}^{\delta}\right) \\
\mathrm{e}^{-M_{\mathrm{a}}}
\end{gathered}
$$

shifting the peak reproductive output towards higher densities, while not affecting reproductive output at densities above the peak (Fig. 1). We varied the value of $\delta$ between 1 (no Allee effect) and 5 (a strong Allee effect) (Myers et al. 1995, Stoner \& Ray-Culp 2000).

Parameter values were set such that the model represented a generalised iteroparous 'marine invertebrate' and equilibrated at reasonable population values: adult reproductive output per time-step (embryo production plus larval survival) $\alpha=1000$, adult mortality per time-step $M_{a}=0.5$ resulting in adult survival probability of 0.61 per time-step; juvenile mortality per time-step $\mathrm{M}_{\mathrm{j}}=2$, resulting in juvenile survival probability of 0.14 per time-step, time to maturity $\tau=3$ timesteps, scaling parameter $\beta=45$. $\beta$ was set empirically; biologically, its role is to ensure that the curves look similar at high density, such that the Allee effect only operates at low density. The model was run for 200 time-steps, by which time it had reached equilibrium.

With the model, we examined the effects of fishing mortality (F) and initial density for different levels of Allee effect $(\delta)$ upon equilibrium population size and critical thresholds. We defined the critical threshold in 3 ways: (1) a critical Allee effect threshold (critical $\delta$ value), above which a population of given density and mortality rate goes extinct; (2) a critical mortality rate, above which a population of given density and Allee effect strength goes extinct; and (3) a critical density threshold, below which a population with a given Allee effect strength and mortality goes extinct.

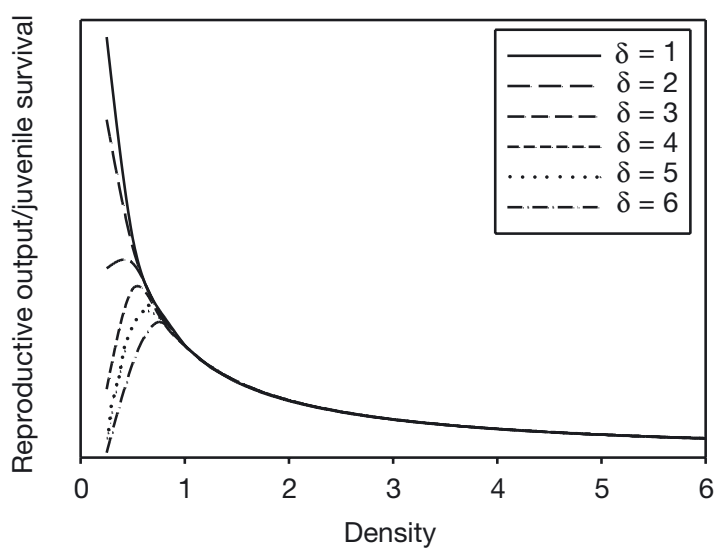

Fig. 1. Effect of changing the value of the exponent $\delta$ in the density dependent equation for reproductive output 


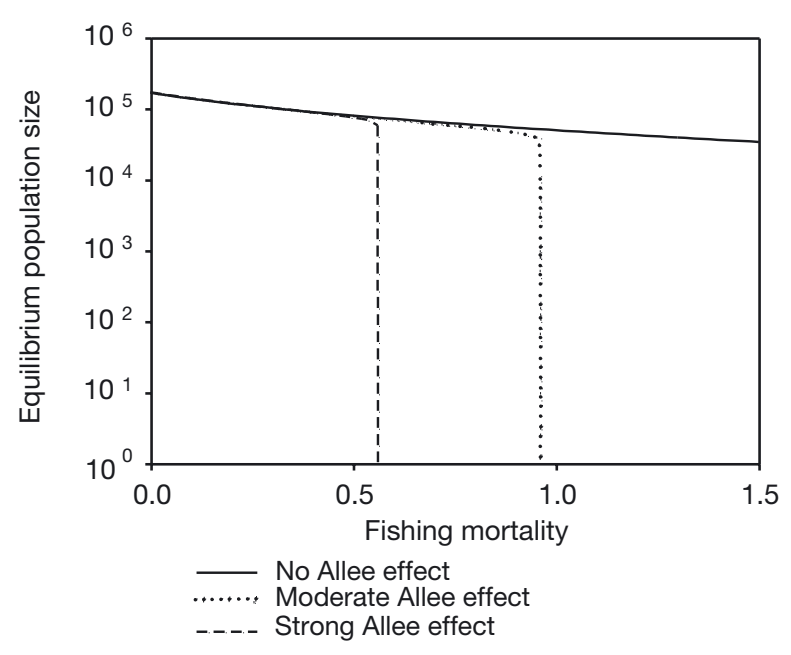

Fig. 2. Fishing mortality and equilibrium population size with varying strength of Allee effect. No Allee effect: $\delta=1$; moderate Allee effect: $\delta=3$; strong Allee effect: $\delta=5$

\section{MODEL RESULTS}

Equilibrium population size for an unexploited population is affected very little by the strength of the Allee effect, while exploitation without an Allee effect causes an approximately exponential decline in equilibrium population size. The most dramatic effect of exploitation on a population with Allee effects is that there is a critical threshold value of fishing mortality, above which the population crashes abruptly to extinction. Such thresholds have been shown in many models incorporating Allee effects (Gerritsen 1980, Dennis 1989, Quinn et al. 1993, Courchamp et al. 1999, Boukal \& Berec 2002). When we varied the strength of the Allee effect, fishing mortality and the Allee effect interacted, such that populations with stronger Allee effects became extinct under lower levels of fishing

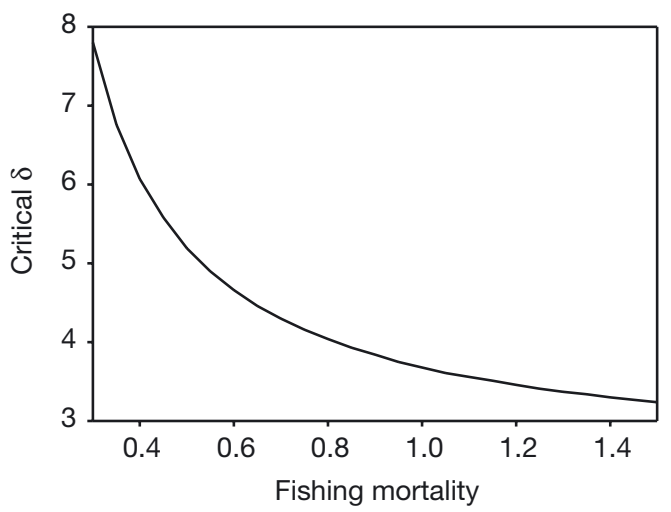

Fig. 3. Relationship between fishing mortality and the strength of Allee effect at which the population goes extinct (critical $\delta$ ). Mortality causes an exponential decline in the strength of Allee effect that causes extinction mortality, or conversely that as fishing mortality increased, weaker Allee effects drove populations extinction (Fig. 2). Additional fishing mortality caused an exponential decline in the critical Allee effect (the Allee effect which drives a population of given size extinction; Fig. 3). It also caused an exponential increase in critical density thresholds (Fig. 4). The modelling results demonstrate that increased fishing mortality (or any other anthropogenic source of mortality) can activate latent demographic Allee effects by (1) reducing population size or density to the Allee threshold and (2) increasing the critical density threshold such that a given component Allee effect has more severe demographic consequences.

\section{EMPIRICAL EVIDENCE}

In general, there have been 2 approaches to the empirical study of Allee effects in marine and terrestrial systems: (1) experimental or observational studies on component Allee effects, with the link to population dynamics sometimes made through modelling; and (2) Allee model fitting to empirical data such as reproductive success or population time-series where there is large variation in population size. Studies of component Allee effects, or possible mechanisms for Allee effects, can show where there are latent Allee effects in a population. Studies of population time-series, however, are looking for demographic Allee effects.

In marine systems, studies of component Allee effects have focused mainly on reproductive success in invertebrates, particularly broadcast spawners. In contrast, studies of demographic Allee effects have focused on searching for evidence of Allee effects in fisheries stock recruitment data or in predator-prey

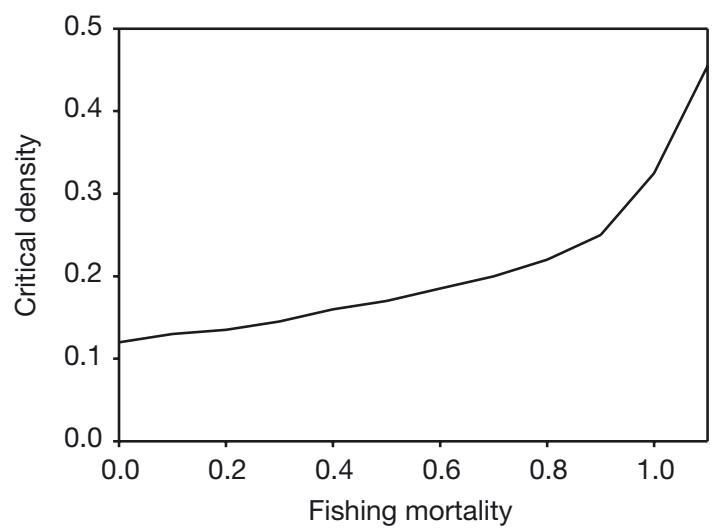

Fig. 4. Relationship between fishing mortality and critical density thresholds for a given strength of Allee effect (in this case, $\delta=3$ ). Increasing fishing mortality causes an exponential-type increase in the critical density below which the population goes extinct 
interactions involving fishery species, as a possible explanation for the collapse and lack of recovery in exploited fish populations.

\section{Broadcast spawners}

Many marine taxa possess a clear-cut mechanism for component Allee effects in their reproductive system: they are sessile or semi-sessile broadcast spawners. Fertilisation success of eggs depends on the concentration of sperm in the water column. The proportion of eggs fertilised declines exponentially with the distance of the female downstream from the nearest male (Fig. 5). At nearest-neighbour distances of $<1 \mathrm{~m}$, models predict that $<0.1 \%$ of eggs will be fertilised under high turbulence (Denny \& Shibata 1989), although fertilisation efficiency varies depending on the taxon and the environment (Pennington 1985, Babcock et al. 1994)

Numerous marine invertebrate taxa are broadcast spawners (Giese \& Kanatani 1987). Most species where the adults are usually sessile, such as corals, anemones, ascidians and sponges, have no other option for sexual reproduction, although they usually also reproduce clonally and may be self-fertile (Carlon 1999). Bivalves, echinoderms and archaeogastropods are also broadcast spawners, although many are somewhat mobile as adults.

In sea urchins, both density and population size have an effect on fertilisation efficiency, with density being critical in small populations but less so in large ones. There is evidence of a trade-off between fertilisation efficiency and competition in several species, implying that there is a positive relationship between density and fertilisation efficiency across the full range of natural densities to the carrying capacity (Levitan et al. 1992, Levitan \& Young 1995). Research has therefore emphasised the importance of Allee effects in these species.

The relationships between population size, density and fertilisation efficiency do not guarantee a demographic Allee effect or even a component Allee effect in reproductive output. In urchins, competition often results in a smaller mean body size rather than higher mortality, since most echinoderms can shrink if resources are scarce (Levitan 1991). In Diadema antillarum, the increase in gamete production by larger individuals at low density seems to offset the reduction in fertilisation efficiency, such that individual reproductive output remains broadly similar across a wide range of densities (Levitan 1991). In addition, many taxa have evolved ecological and physiological mechanisms to avoid sperm limitation, so in natural (nonexperimental) systems, may be well adapted for effi- cient fertilisation even at low density (Yund 2000). Moreover, various invertebrates show negatively density dependent predation mortality at low population densities (Seitz et al. 2001), which could offset component Allee effects in reproduction.

The populations of many broadcast spawners have suffered dramatic reductions in density through exploitation. There has been heavy exploitation of sea urchins (Pfister \& Bradbury 1996), sea cucumbers (Uthicke \& Benzie 2001), Eastern oysters (Hargis 1999), scallops (Murawski et al. 2000) and abalone (Farlinger \& Campbell 1992, Guzman del Proo 1992, Parker et al. 1992, Tegner et al. 1992). Recent major disease outbreaks in corals and Diadema antillarum, and seem to be unprecedented in recent even in geological history (Lessios et al. 1984, Aronson \& Precht 2001). Is there evidence that a component Allee effect from broadcast spawning has had demographic consequences in these exploited populations?

There are several examples where populations subjected to exploitation have collapsed rapidly (e.g. abalone: Farlinger \& Campbell 1992, Guzman del Proo 1992, Parker et al. 1992, Tegner et al. 1992; urchins: Lesser \& Walker 1998, Kalvass 2000). This fits well with
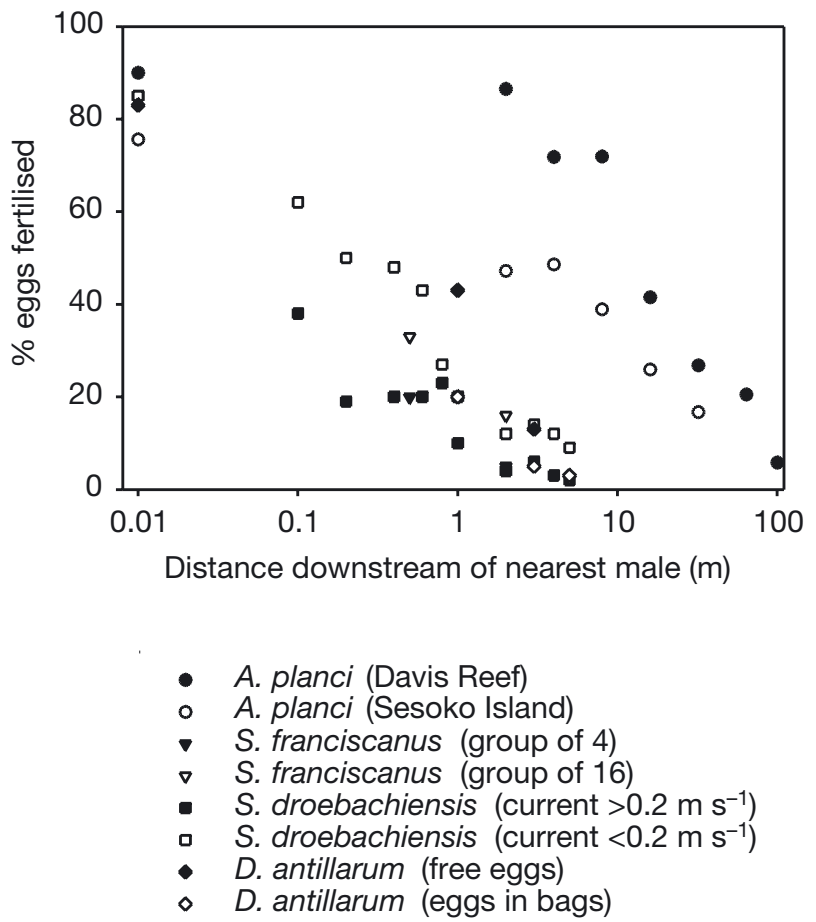

Fig. 5. Fertilisation success in echinoderms, showing a general trend of exponential decline in the proportion of eggs fertilised with distance downstream of the nearest male. Data from: Babcock et al. 1994 (crown of thorns starfish Acanthaster planci); Levitan et al. 1992 (red sea urchin Strongylocentrotus franciscanus); Pennington 1985 (green sea urchin S. droebachiensis); Levitan 1991 (Caribbean long-spined sea urchin Diadema antillarum) 
the results of our model, which indicate that Allee effects result in critical thresholds above which populations collapse rapidly, and that such critical thresholds are strongly affected by increases in fishing mortality.

There is evidence from the geological record that, within taxa which have a diverse variety of life histories (e.g. corals, gastropods), species with brooding larvae survived better through times of stress, implying that they can recover more easily from episodes of reduced density or population size (Wray 1995). Aronson \& Precht (2001) suggested that Allee effects are implicated in the failure of the corals Acropora palmata and $A$. cervicornis to recover from the disease and bleaching outbreaks of the 1980s and 1990s. Both species broadcast eggs and sperm, with fertilisation in the water column and planktotrophic larvae. They have been largely replaced on Caribbean reefs for the first time in recent geological history by Agaricia and Porites, which are brooding species where eggs are retained by the females during and after fertilisation, reducing problems of sperm limitation by eliminating the need for 2 gametes to meet in the water column.

Aside from the effects of decreased population size or density and increased mortality, evolved mechanisms for avoiding sperm limitation may break down at low density. In abalone, a decreasing proportion of reproductive adults participates in reproductive aggregations in heavily fished, low density populations (Shepherd \& Brown 1993). Abalone species have been serially depleted along NE Pacific coasts, demonstrating the rapidity with which each population collapsed after the fishery focused on it (Fig. 6).

Abalone may be unable to support heavy fishing mortality at any density - i.e. the decline in population

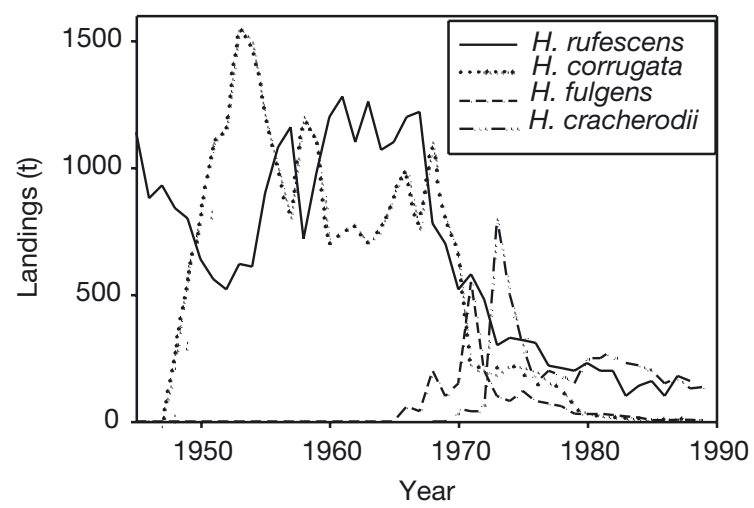

Fig. 6. Population size of abalone species (red abalone Haliotis rufescens; pink abalone $H$. corrugata; green abalone $H$. fulgens; black abalone $H$. cracherodii) in California. Note the pattern of serial collapse as the fisheries move on to each species in turn. Red are the preferred species for the fishery, followed by pink, green and black. Data from Parker et al. 1992, Tegner et al. 1992 growth rate may not be density dependent, as would be required for a demographic Allee effect. To test this, we examined landings of red and pink abalone, which have the longest time series. If we assume that landings are proportional to population size, the ratio of landings at time $t+1$ to landings at time $t$ is an estimate of the average population growth rate over the year. The relationship between estimated population growth rate and landings is significantly positive (Figs. $7 \& 8$ ), suggesting that population growth rate increases with population size. This is suggestive of a demographic Allee effect, although it could also be a function of changes in effort.

\section{Reproduction in non-broadcast spawners}

There are few experimental studies on Allee effects in marine systems not related to fertilisation efficiency in broadcast spawners. In general, non-broadcast spawners have been considered too mobile and too behaviourally sophisticated to suffer from reproductive Allee effects; however, there are some exceptions. In queen conch Strombus gigas, a heavily exploited Caribbean gastropod, there is a positive relationship between density and per capita reproductive activity at low density (Stoner \& Ray-Culp 2000). This has been interpreted as an Allee effect related to the decreasing probability of encountering a mate at low density.

An observational study cannot demonstrate a causal relationship between per capita reproductive output and density. There are alternative explanations for observed correlations; for example, conch may migrate away from high density reproductive aggregations when reproductively spent, or there may be an ontoge-

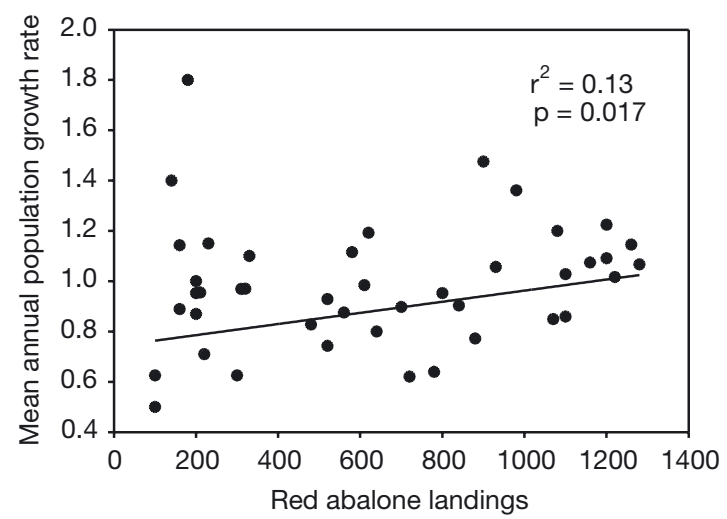

Fig. 7. Mean annual population growth rate of red abalone, on the assumption that landings are proportional to the population size (ratio of landings at time $t+1$ to landings at time $t$ ) vs landings in metric tonnes. A positive slope indicates the possibility of an Allee effect, with an Allee threshold (population growth rate $=1$ ) at the population level which provides landings of $\sim 1200 \mathrm{t}$ 
netic shift from low density/non-reproductive young adults to high density/reproductive adults. This is not to say that Allee effects are not important, but rather, that the evidence for Allee effects in queen conch is indirect (including vulnerability to fishing pressure, as predicted in the model, and failure to recover when fishing is stopped, e.g. in Bermuda and Florida; Berg et al. 1992a,b). Such studies illustrate the difficulty of demonstrating Allee effects in natural populations.

Sperm limitation can be an issue at low density, even in mobile animals, particularly when the mechanism for density reduction is fishing, since this also reduces the proportion of older and larger males (Fig. 9). Potential sperm limitation has been demonstrated in the New Zealand rock lobster Jasus edwardsii, the Caribbean spiny lobster Panulirus argus and the blue crab Callinectes sapidus, all of which are fished heavily and where large males are targeted. Smaller males and fewer matings result in smaller female clutch sizes and a higher proportion of unfertilised females (MacDiarmid \& Butler 1999, Kendall et al. 2001, P. Jivoff pers. comm.).

Sperm limitation in crabs and lobsters may or may not reduce female fitness at low density (i.e. a component Allee effect). These species possess other life history components that mitigate the impact of component Allee effects at the population level. Rock and spiny lobster have an exceptionally long larval duration (several months; Lipcius \& Eggleston 2000), which decouples local recruitment from local reproductive success (Lipcius et al. 1997, 2001). The blue crab also has larval mixing on a broad scale and is cannibalistic, such that low adult density may improve juvenile survival (Moksnes et al. 1997) and female reproductive output (Lipcius \& Stockhausen 2002). Nonetheless, if fishing pressure is substantial across the entire metapopulation, which is likely in these species, demographic Allee effects may occur.

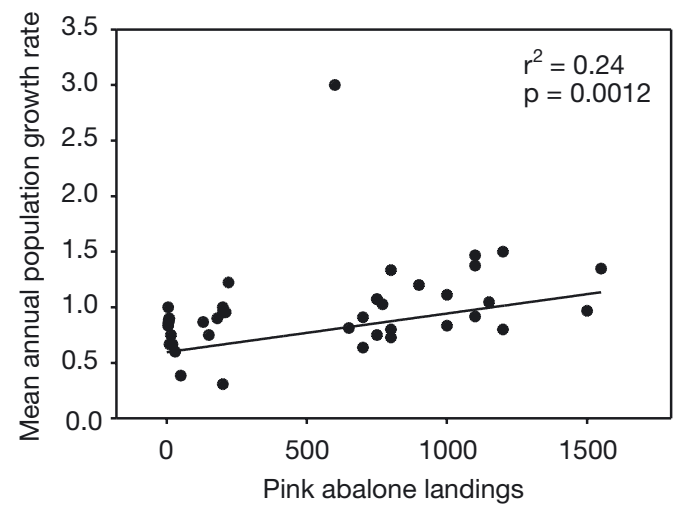

Fig. 8. As for Fig. 7 but for pink abalone. Again, a positive slope indicates a potential Allee effect with a threshold at landings of $\sim 1200 \mathrm{t}$

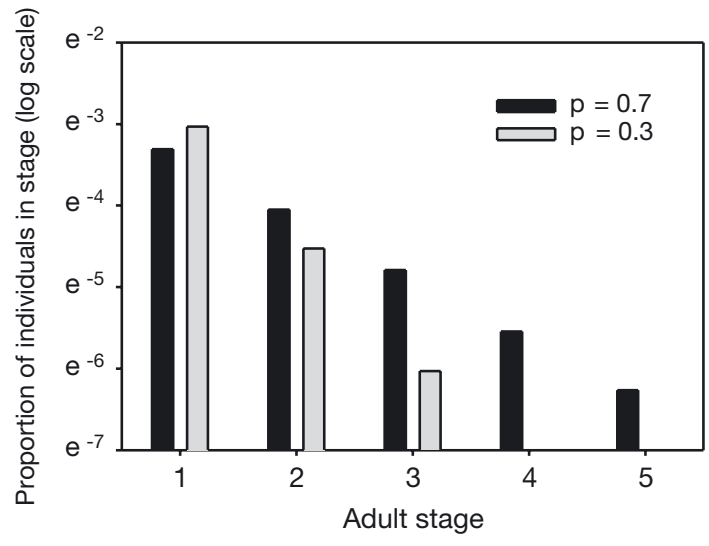

Fig. 9. Age structure of populations with different probabilities of survival (p) from one stage to the next. Data from a simple density independent matrix population model. High $p$ $(0.7)$ corresponds to low mortality (i.e. the unfished scenario), while low p (0.3) corresponds to high mortality (i.e. the fished scenario). Note that even though all stages have an equal survival probability in each case, the lower survival probability (higher mortality) scenario results in a depletion of older stages relative to younger ones. Hence, a fishery that targets all individuals in the population equally still alters the age structure by reducing the proportion of older individuals

\section{Survival-related Allee effects}

Positive density dependence in individual survival also constitutes a component Allee effect. For example, survival due to predation will be positively density dependent where predators have a Type II functional response (Holling 1959) with a limited aggregative or numerical response (Fig. 10). This is an interesting mechanism in that it is not linked to specific life history traits such as broadcast spawning.

Positive density dependence in survival during some life stage has been demonstrated experimentally in a number of marine species, including queen conch (Marshall 1992, Ray \& Stoner 1994), New Zealand rock lobster (Butler et al. 1999), Caribbean spiny lobster (Mintz et al. 1994), red sea urchins Strongylocentrotus franciscanus (Quinn et al. 1993), Pacific salmonids (Wood 1987), soft-shell clams Mya arenaria (Lipcius \& Hines 1986), Eastern oysters Crassostrea virginica (Eggleston 1990), marine insects (Foster \& Treherne 1981) and zooplankton (Folt 1987); see Seitz et al. (2001) for a review for marine bivalves. The survival of one life history stage may be positively related to the density of another; for example, newly settled red sea urchins, Eastern oysters Crassostrea virginica and mussels Mytilus edulis survive better under adult canopies (Rowley 1989, Quinn et al. 1993, R. Mann pers. comm.), and adult cod feed on the competitors and predators of juvenile cod (Walters \& Kitchell 2001). With the exception of red sea urchins (Botsford et al. 


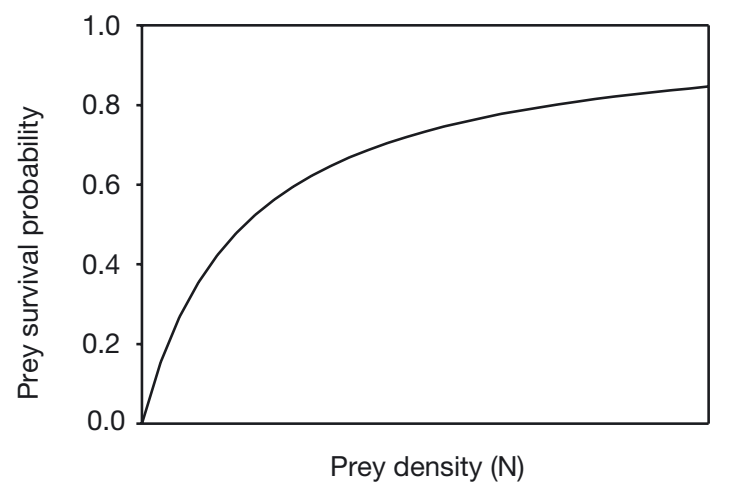

Fig. 10. Prey survival probability due to predation as a function of prey density, where predators have a Type II functional response and constant numbers

1993, Quinn et al. 1993, Pfister \& Bradbury 1996) and other fished species (e.g. Peterman \& Gatto 1978, Hilborn \& Walters 1992), these results have not been linked to demographic Allee effects.

Human 'predation' can be a mechanism for creating component Allee effects in survival (Hilborn \& Walters 1992). An exploitation Allee effect occurs when the per capita exploitation rate increases as population size or density decreases. There are, for example, situations where decreasing population size does not result in decreasing population density (e.g. schooling fish, spawning aggregations), and in this case, a reduction in population size will not make individuals any harder to catch. Hence, if effort is constant, total catch will remain more or less constant, and the proportion of individuals caught (the per capita exploitation rate) will increase as population size decreases, creating an Allee effect (= depensatory fishing mortality). Another possibility is for effort to increase as catch per unit effort declines (this is usual, given economic investments in fisheries), so that catches decrease at a lower rate than population size, again resulting in an increase in the per capita exploitation rate. Note, however, that these Allee effects will only operate under exploitation; elimination of exploitation also removes the Allee effect. Therefore, exploitation Allee effects will affect the rate at which a population declines under heavy exploitation, but will not affect the rate at which populations recover if exploitation stops, unlike Allee effects intrinsic to species life history or ecology.

\section{Demographic Allee effects}

For fish, as for mobile invertebrates, Allee effects were not considered likely to be important, until the failure of several populations to recover from overexploitation after substantial reductions in fishing effort led to a debate about the possibility of recruitment failure and low or negative per capita population growth rates at low density (demographic Allee effects). This work has focused on fitting models with and without Allee effects to population size and recruitment data, which is possible only for (economically important) species for which such data sets exist. In a database of population size and recruitment for 128 fish stocks, 26 allowed an analysis with high statistical power (>0.95) and there was significant evidence of Allee effects in only 3 of them (Myers et al. 1995). Myers concluded that Allee effects were not of widespread importance, and collapses and recovery failures should be attributed to other causes.

The large variance in stock recruitment data means that there may be limited statistical power to detect Allee effects in time-series data, and the failure to reject a null hypothesis of no Allee effects might not be an indicator that they are not present (Liermann \& Hilborn 1997, Shelton \& Healey 1999). In addition, there is often uncertainty about what constitutes a 'stock', which should be a population or subpopulation that is more or less reproductively isolated. If the stock considered by managers actually consists of several substocks, the impact of Allee effects and extinctions at the substock level may be masked until the metapopulation reaches a critical point (Courchamp et al. 2000a, Frank \& Brickman 2000). Conversely, if the 'stock' is only part of a much larger open population, recruitment will be decoupled from local individual fitness, even if component Allee effects due to density are important (i.e. component Allee effects will not lead to demographic Allee effects until a critical point is reached across the whole population).

There is indirect evidence for Allee effects in some exploited fish species, particularly gadids (the cod family). An analysis of recovery from exploitation in 90 fish populations showed that $15 \mathrm{yr}$ after major declines in stock size, $40 \%$ of the populations (mainly gadids) showed no recovery, with $48 \%$ showing only marginal recovery (Hutchings 2000).

\section{CONCLUSIONS}

Our model suggests that increases in mortality, such as those due to fishing, interact very strongly with Allee effects, to increase population size or density thresholds below which the population is driven to extinction. Exploitation therefore has the potential to render populations very vulnerable to collapse when Allee effects are present. There is no a priori reason for Allee effects to be intrinsically unlikely in marine populations, notwithstanding their (possibly) open, metapopulation structure. Despite this, our analysis of 
the empirical data on Allee effects in diverse marine species revealed numerous suggestive observations, but very little firm evidence. Does this mean that Allee effects can be dismissed as unusual or insignificant in marine populations?

The failure to demonstrate Allee effects convincingly in marine populations might in fact be methodological. There is a lack of clear understanding on the part of many ecologists as to the precise definition of Allee effects. Allee effects require a causal relationship between density or population size and either a component of individual fitness (component Allee effects; sensu Stephens et al. 1999) or the per capita population growth rate at low density (demographic Allee effects; sensu Stephens et al. 1999). Correlations between density and fitness can have various explanations, including mutual dependence on a third variable such as site or age. Showing a causal relationship between 2 variables is an age-old problem for ecologists, to which we do not have a solution, except to say that clear demonstrations of component Allee effects are likely to require large-scale manipulative experiments, and will therefore be limited to a few taxa.

Another issue is that of temporal lags. Our model assumes that population equilibria adjust very rapidly to changes in demographic rates such as reproduction. This is not the case in long-lived species, where populations equilibrate only slowly. In this case, thresholds, while still present as unstable equilibria in the underlying model, are visible only as gradual declines over a long time period, rather than as abrupt crashes. This smearing out of thresholds, plus the usual time scale of scientific research, might make the presence of Allee effects difficult to verify in a large category of longlived exploited species, including gadids and abalone.

Given constraints on assessing Allee effects in marine populations, we feel that a promising tactic is to model potentially vulnerable populations with different strengths of Allee effect (e.g. Fig. 2). This approach gives a prediction of the likely consequences of different scenarios if Allee effects are important. This is particularly useful for exploited populations in the context of precautionary management. If Allee effects are strong, spatial considerations become critical. Traditional fisheries management, with control of inputs (effort) or outputs (landings), may not be very successful because it allows fishers to target dense areas and tends to reduce a population to uniform low density. Spatial management measures, such as no-take reserves, maintain areas of high population density, and are a better management option where Allee effects may be a risk.

Our model, and Allee effect/exploitation models presented elsewhere (e.g. Botsford et al. 1993, Quinn et al. 1993, Pfister \& Bradbury 1996) demonstrate that Allee effects can have major consequences for population dynamics, sustainable exploitation and management. The potential population consequences of mechanisms for component Allee effects remain unexplored in most marine species. We contend that this limits both our ecological understanding and the probable success of conservation for marine species.

Acknowledgements. We thank R. Mann and M. Patterson (School of Marine Science, College of William and Mary) for improving the manuscript, and S. Schreiber (College of William and Mary), F. Courchamp (Université Paris Sud) and R. Myers (Dalhousie University) for constructive discussions on Allee effects. Funding support was provided by the National Science Foundation-Biological Oceanography Program, National Undersea Research Program-Caribbean Marine Research Centre, the International Society for Reef Studies, the International Women's Fishing Association and the Commonwealth of Virginia. This is contribution 2588 from the Virginia Institute of Marine Science.

\section{LITERATURE CITED}

Allee WC (1938) Animal aggregations: a study in general sociology. University of Chicago Press, Chicago

Aronson RB, Precht WF (2001) White-band disease and the changing face of Caribbean coral reefs. Hydrobiologia 460:25-38

Babcock RC, Mundy CN, Whitehead D (1994) Sperm diffusion models and in situ confirmation of long-distance fertilisation in the free-spawning asteroid Acanthaster planci. Biol Bull (Woods Hole)186:17-28

Barber PH, Palumbi SR, Erdmann MV, Moosa KM (2000) A marine Wallace's line? Nature 406:692-693

Berg CJ, Couper F, Nisbet K, Ward J (1992a) Stock assessment of queen conch, Strombus gigas, and harbour conch, Strombus costatus, in Bermuda. Proc Gulf Caribb Fish Inst 41:433-438

Berg CJ, Glazer R, Carr J, Krieger J, Acton S (1992b) Status of the queen conch, Strombus gigas, in Florida waters: a progress report. Proc Gulf Caribb Fish Inst 41:439-443

Botsford LW, Quinn JF, Wing SR, Brittnacher JG (1993) Rotating spatial harvest of a benthic invertebrate, the red sea urchin Strongylocentrotus franciscanus. In: Kruse G, Eggers DM, Marasco RJ, Pautzke C, Quinn (eds) Proc Int Symp Manage Strategies Exploited Fish Pop. Alaska Sea Grant College Program, AK-SG-93-01. Alaska Sea Grant, Fairbanks, AK, p 409-428

Boukal DS, Berec L (2002) Single-species models of the Allee effect: extinction boundaries, sex ratio and mate encounters. J Theor Biol 128:375-394

Butler MJ IV, MacDiarmid AB, Booth JD (1999) The cause and consequence of ontogenetic change in social aggregation in New Zealand spiny lobsters. Mar Ecol Prog Ser 188: 179-191

Calvert WH, Hedrick LE, Brower LP (1979) Mortality of the monarch butterfly (Danaus plexippus L.): avian predation at five overwintering sites in Mexico. Science 204:847-851

Carlon DB (1999) The evolution of mating systems in tropical reef corals. Trends Ecol Evol 14:491-495

Caswell H (2001) Matrix population models: construction, analysis and interpretation. Sinauer Associates, Sunderland, MA

Clutton-Brock TH, Gaynor D, McIlrath GM, MacColl ADC 
and five others (1999) Predation, group size and mortality in a cooperative mongoose, Suricata suricatta. J Anim Ecol 68:672-683

Courchamp F, Macdonald DW (2001) Crucial importance of pack size in the African wild dog Lycaon pictus. Anim Cons 4:169-174

Courchamp F, Clutton-Brock T, Grenfell B (1999) Inverse density dependence and the Allee effect. Trends Ecol Evol 14:405-410

Courchamp F, Clutton-Brock T, Grenfell B (2000a) Multipack dynamics and the Allee effect in the African wild dog, Lycaon pictus. Anim Cons 3:277-285

Courchamp F, Clutton-Brock T, Grenfell B (2000b) Impact of natural enemies on obligately cooperative breeders. Oikos 91:311-322

Cowan RK, Lwize KMM, Sponaugle S, Paris CB, Olson DB (2000) Connectivity of marine populations: open or closed? Science 287:857-859

Crowder LB, Lyman SJ, Figueira WF, Priddy J (2000) Sourcesink population dynamics and the problem of siting marine reserves. Bull Mar Sci 66:799-820

Dayton PK, Tegner MJ, Edwards PB, Riser KL (1998) Sliding baselines, ghosts and reduced expectations in kelp forest communities. Ecol Appl 8(2):309-322

Dennis B (1989) Allee effects: population growth, critical density and the chance of extinction. Nat Resour Model 3: 481-538

Denny MW, Shibata MF (1989) Consequences of surf-zone turbulence for settlement and external fertilisation. Am Nat 117:838-840

Eggleston DB (1990) Foraging behaviour of the blue crab, Callinectes sapidus, on juvenile oysters, Crassostrea virginica: effects of prey density and size. Bull Mar Sci 46(1): 62-82

Farlinger S, Campbell A (1992) Fisheries management and biology of northern abalone, Haliotis kamtschatkana, in the northeast Pacific. In: Shepherd SA, Tegner MJ, Guzman del Proo SA (eds) Abalone of the world: biology, fisheries and culture. Fishing News Books, Oxford, p 395-406

Folt CL (1987) An experimental analysis of costs and benefits of zooplankton aggregation. In: Kerfoot WC, Sih A (eds) Predation: direct and indirect impacts on aquatic communities. University Press of New England, Hanover, NH, p 300-314

Ford SE, Tripp MR (1996) Diseases and defence mechanisms. In: Kennedy VS, Newell R, Eble AS (eds) The Eastern oyster. Maryland Sea Grant, College Park, MD, p 581-660

Foster WA, Treherne JE (1981) Evidence for the dilution effect in the selfish herd from fish predation on a marine insect. Nature 293:466-467

Fowler CW, Baker JD (1991) A review of animal population dynamics at extremely reduced population levels. Rep Int Whal Comm 41:545-554

Frank KT, Brickman D (2000) Allee effects and compensatory population dynamics within a stock complex. Can J Fish Aquat Sci 57:513-517

Garcia S, Newton C (1997) Current situation, trends and prospects in world capture fisheries. In: Pikitch EK, Huppert DD, Sissenwine MP (eds) Proceeding of the symposium on global trends in fisheries management, Seattle, Washington, 14-16 June 1994. American Fisheries Society, Bethesda, MD, p 3-27

Gerritsen J (1980) Sex and parthenogenesis in sparse populations. Am Nat 115:718-742

Giese AC, Kanatani H (1987) Maturation and spawning. In: Giese AC, Pearse JS, Pearse VB (eds) Reproduction in marine invertebrates, Vol IX. General aspects: Seeking unity in diversity, Boxwood Press, Pacific Grove, CA, p 251-329

Guzman del Proo SA (1992) A review of the biology of abalone and its fishery in Mexico. In: Shepherd SA, Tegner MJ, Guzman del Proo SA (eds) Abalone of the world: biology, fisheries and culture. Fishing News Books, Oxford, p 341-360

Halliday TR (1980) The extinction of the passenger pigeon Ectopistes migratorius and its relevance to contemporary conservation. Biol Conserv 17:157-162

Hargis WJ (1999) Evolution of the Chesapeake oyster reef system during the Holocene epoch. In: Luckenbach MW, Mann R, Wesson JA (eds) Oyster reef habitat restoration: a synopsis and synthesis of approaches. Virginia Institute of Marine Science Press, Gloucester Point, VA, p 5-23

Hilborn R, Walters CJ (1992) Quantitative fisheries stock assessment: choice, dynamics and uncertainty. Chapman \& Hall, London

Holling CS (1959) Some characteristics of simple types of predation and parasitism. Can Entomol 91(7):385-398

Hutchings JA (2000) Collapse and recovery of marine fishes. Nature 406:882-885

Inman AJ, Krebs J (1987) Predation and group living. Trends Ecol Evol 2(2):31-32

Jackson JBC, Kirby MX, Berger WH, Bjorndal KA and 15 others (2001) Historical overfishing and the recent collapse of coastal ecosystems. Science 293:629-638

Jennings S, Polunin NVC (1996) Effects of fishing effort and catch rate upon the structure and biomass of Fijian reef fish communities. J Appl Ecol 33:400-412

Jones GP, Milicich MJ, Emslie MJ, Lunow C (1999) Selfrecruitment in a coral reef fish population. Nature 402: 802-805

Kalvass PE (2000) Riding the rollercoaster: boom and decline in the California red sea urchin fishery. J Shellfish Res 19(1):621-622

Kendall MS, Wolcott DL, Wolcott TG, Hines AH (2001) Reproductive potential of individual male blue crabs, Callinectes sapidus, in a fished population: depletion and recovery of sperm number and seminal fluid. Can J Fish Aquat Sci 58(6):1168-1177

Kenward RE (1978) Hawks and doves: factors affecting success and selection in goshawk attacks on woodpigeons. J Anim Ecol 47:449-460

Kuussaari M, Saccheri I, Camara M, Hanski I (1998) Allee effect and population dynamics in the Glanville fritillary butterfly. Oikos 82:384-392

Lesser MP, Walker CW (1998) Overexploitation of the urchin fishery: does history repeat itself and is there anything we can do to ensure a sustainable yield to the market? J Shellfish Res 17(1):331

Lessios HA, Robertson DR, Cubit JD (1984) Spread of Diadema mass mortality through the Caribbean. Science 226:335-337

Levitan DR (1991) Influence of body size and population density on fertilisation success and reproductive output in a freespawning invertebrate. Biol Bull (Woods Hole) 181:261-268

Levitan DR, Young CM (1995) Reproductive success in large populations: empirical measures and theoretical predictions of fertilisation in the sea biscuit Clypeaster rosaceus. J Exp Mar Biol Ecol 190:221-241

Levitan DR, Sewell MA, Chia FS (1992) How distribution and abundance influence fertilisation success in the sea urchin Strongylocentrus franciscanus. Ecology 73:248-254

Liermann M, Hilborn R (1997) Depensation in fish stocks: a hierarchic Bayesian meta-analysis. Can J Fish Aquat Sci 54(9):1976-1984 
Lipcius RN, Hines AH (1986) Variable functional responses of a marine predator in dissimilar homogeneous microhabitats. Ecology 67:1361-1371

Lipcius RN, Eggleston DB (2000) Ecology and fishery biology of spiny lobsters. In: Phillips B, Kittaka J (eds) Spiny lobster management: fisheries and aquaculture. Fishing News Books, Oxford, p 1-41

Lipcius RN, Stockhausen WT (2002) Concurrent decline of the spawning stock, recruitment, larval abundance, and size of the blue crab Callinectes sapidus in Chesapeake Bay. Mar Ecol Prog Ser 226:45-61

Lipcius RN, Stockhausen WT, Eggleston DB, Marshall LS, Hickey B (1997) Hydrodynamic decoupling of recruitment, habitat quality and adult abundance in the Caribbean spiny lobster: source-sink dynamics? Mar Freshw Res 48:807-815

Lipcius RN, Stockhausen WT, Eggleston DB (2001) Marine reserves for Caribbean spiny lobster: empirical evaluation and theoretical metapopulation dynamics. Mar Freshw Res 52:1589-1598

MacDiarmid AB, Butler MJ IV (1999) Sperm economy and limitation in spiny lobsters. Behav Ecol Sociobiol 46(1):14-24

Marshall LS (1992) Survival of juvenile queen conch Strombus gigas in natural habitats: impact of prey, predator and habitat features. PhD dissertation, School of Marine Science, College of William and Mary, VA

Mintz JD, Lipcius RN, Eggleston DB, Seebo MS (1994) Survival of juvenile Caribbean spiny lobster: effects of shelter size, geographic location and conspecific abundance. Mar Ecol Prog Ser 112:255-266

Moksnes PO, Lipcius RN, Pihl L, Van Montfrans J (1997) Cannibal-prey dynamics in young juveniles and postlarvae of the blue crab. J Exp Mar Biol Ecol 215(2):157-187

Murawski SA, Brown R, Lai HL, Rago P, Hendrickson L (2000) Large-scale closed areas as a fishery-management tool in temperate marine systems: the Georges Bank experience. Bull Mar Sci 66(3):775-798

Myers RA, Worm B (2003) Rapid worldwide depletion of predatory fish communities. Nature 243:280-283

Myers RA, Barrowman NJ, Hutchings JA, Rosenberg AA (1995) Population dynamics of exploited fish stocks at low population levels. Science 269:1106-1108

Parker DO, Haaker PL, Togstad HA (1992) Case histories for three species of California abalone, Haliotis corrugata, $H$. fulgens and H. cracherodii. In: Shepherd SA, Tegner MJ, Guzman del Proo SA (eds) Abalone of the world: biology, fisheries and culture. Fishing News Books, Oxford, p 384-394

Pauly D, Christensen V, Dalsgaard J, Froese R, Torres F (1998) Fishing down marine food webs. Science 279: 860-863

Pennington JT (1985) The ecology of fertilisation of echinoid eggs: the consequences of sperm dilution, adult aggregation and synchronous spawning. Biol Bull (Woods Hole) 169:417-430

Peterman RM, Gatto M (1978) Estimation of functional responses of predators on juvenile salmon. J Fish Res Board Can 35:797-808

Petersen CW, Levitan DR (2001) The Allee effect: a barrier to recovery by exploited species. In: Reynolds JD, Mace GM, Redford KH, Robinson JG (eds) Conservation of exploited species. Cambridge University Press, Cambridge, p 281-300

Editorial responsibility: Otto Kinne (Editor),

Oldendorf/Luhe, Germany
Pfister CA, Bradbury A (1996) Harvesting red sea urchins: recent effects and future predictions. Ecol Appl 6(1): 298-310

Quinn JF, Wing SR, Botsford LW (1993) Harvest refugia in marine invertebrate fisheries: models and applications to the red sea urchin Strongylocentrus franciscanus. Am Zool 33:537-550

Ray M, Stoner AW (1994) Experimental analysis of growth and survivorship in a marine gastropod aggregation: balancing growth with safety in numbers. Mar Ecol Prog Ser 105:47-59

Rowley RJ (1989) Settlement and recruitment of sea urchins (Strongylocentrotus spp.) in a sea-urchin barren ground and a kelp bed: are populations regulated by settlement or post-settlement processes? Mar Biol 100:485-494

Seitz RD, Lipcius RN, Hines AH, Eggleston DB (2001) Density-dependent predation, habitat variation and the persistence of marine bivalve prey. Ecology 82(9): $2435-2451$

Shelton PA, Healey BP (1999) Should depensation be dismissed as a possible explanation for the lack of recovery of the northern cod (Gadus morhua) stock? Can J Fish Aquat Sci 56:1521-1524

Shepherd SA, Brown LD (1993) What is an abalone stock? Implications for the role of refugia in conservation. Can J Fish Aquat Sci 50:2001-2009

Stephens PA, Sutherland WJ, Freckleton RP (1999) What is the Allee effect? Oikos 87(1):185-190

Shinn EA, Smith GW, Prospero JM, Betzer P, Hayes ML, Garrison V, Barber RT (2000) African dust and the demise of Caribbean coral reefs. Geophys Res Lett 27(19): 3029-3032

Stoner AW, Ray-Culp M (2000) Evidence for Allee effects in an over-harvested marine gastropod: density-dependent mating and egg production. Mar Ecol Prog Ser 202: 297-302

Swearer SE, Caselle JE, Lea DW, Warner RR (1999) Larval retention and recruitment in an island population of a coral reef fish. Nature 402:799-802

Tegner MJ, DeMartini JD, Karpov K (1992) The California red abalone fishery: a case study in complexity. In: Shepherd SA, Tegner MJ, Guzman del Proo SA (eds) Abalone of the world: biology, fisheries and culture. Fishing News Books, Oxford, p 370-383

Uthicke S, Benzie JAH (2001) Effect of beche-de-mer fishing on densities and size structure of Holothuria nobilis populations on the Great Barrier Reef. Coral Reefs 19(3): 271-276

Walters C, Kitchell JF (2001) Cultivation/depensation effects on juvenile survival and recruitment: implications for the theory of fishing. Can J Fish Aquat Sci 58:39-50

Watson R, Pauly D (2001) Systematic distortions in world fisheries catch trends. Nature 414:534-536

Wood CC (1987) Predation of juvenile Pacific salmon by the common merganser (Mergus merganser) on eastern Vancouver Island. I: Predation during the seaward migration. Can J Fish Aquat Sci 44:941-949

Wray GA (1995) Evolution of larvae and developmental modes. In: McEdwards L (ed) Ecology of marine invertebrate larvae. CRC Press, Boca Raton, FL

Yund PO (2000) How severe is sperm limitation in natural populations of marine free-spawners? Trends Ecol Evol 15(1):10-13

Submitted: March 31, 2003; Accepted: November 25, 2003 Proofs received from author(s): March 3, 2004 